Vietnam Academy of Science and Technology
Vietnam Journal of Earth Sciences
Website: http://www.vjs.ac.vn/index.php/jse

\title{
Monitoring influence of urbanization on urban thermal environment using multi-temporal LANDSAT imagery: application to Da Nang city
}

\author{
Dang Trung Tu, Nguyen Thi Thu Ha*, Nguyen Thi Mai Ngan, Pham Thi Nhung
}

VNU University of Science

Accepted 25 December 2015

\begin{abstract}
This study illustrates urbanization in Da Nang city and its impacts on local thermal environments using remote sensing. In this study, multi-generation Landsat images from 1990, 1995, 2000, 2005, 2010 and 2014, were used to assess the city's urban expansion and accompanied land surface temperature (LST) characteristics. Results showed that Da Nang urban expanded twice in 2014 (8,634 ha) comparing to 1990 (4,485 ha) and high temperature anomalies were closely associated with built-up and bare-soil land-covers. As consequence, areas covered by the highest LST correspondently expanded from center of Thanh Khe, Hai Chau districts to mostly all 6 present downtown districts. The mean LST difference between the urban downtown area and the suburban area tends to increase over time, from $7.3^{\circ} \mathrm{C}$ in 1990 to $11.9^{\circ} \mathrm{C}$ in 2014 . In the context of moving towards "a friendly environmental Da Nang city", this study provides useful information for understanding the local climatic and environment changes that occurred during rapid urbanization.
\end{abstract}

Keywords: Urbanization, Land surface temperature, impervious surface, Landsat, Da Nang.

(C2015 Vietnam Academy of Science and Technology

\section{Introduction}

Urbanization and urban expansion are the dominant factors in regional landscape evolution across the world, and can significantly affect local climate. Rapid urbanization, particularly in a developing country such as Vietnam, results from the large-scale development of commercial, manufacturing and transportation areas. Urbanization alters the thermal properties of the land, changes the energy budget at the ground surface, changes the surrounding atmospheric circulation characteristics, generates a great amount of anthropogenic waste heat, and leads to a series of changes in the urban environmental

*Corresponding author, Email: hantt_kdc@ @ vnu.edu.vn system (Huang et al., 2009). The increased heat in urban areas requires an increase in the amount of energy used for cooling buildings, leading to a deterioration of air quality and negative health effects (Sailor, 2002). It is believed that the urban heat island, a considered urban thermal environment problem, is more related to urban design, than to development density (Rodgers et al., 2001), therefore quantitative studies on relationship between urban land-cover change and land surface temperature (LST) may help us in future urban "thermally efficient" planning.

Remote sensing provides a straightforward and consistent way to determine LST pattern in a wide region, as well as the thermal differences between urban and rural areas. The Landsat data is one of the most widely used satellite images for 


\section{D.T. Tu, et al./Vietnam Journal of Earth Sciences 37 (2015)}

LST retrieving because of its high resolution (120 $\mathrm{m}$ of TM, $60 \mathrm{~m}$ of ETM+ and $100 \mathrm{~m}$ of TIRs) and free download availability from the website of United States Geological Survey (USGS). Landsat images have been widely used in land use classification, urban heat island research, thermal environment and hydrological investigation in urban or even larger scales (Weng, 2001, Chen et al., 2006, Li et al., 2015; Shi et al., 2015). In Vietnam, Landsat have been used to detect thermal characteristics of urban surfaces in large cities such as Ho Chi Minh (Van and Bao, 2010; 2015), Hanoi (Castrence et al., 2014). Almost studies concentrated on converting radiance into surface brightness temperature and then into LST (Van and Bao, 2008; 2015) from single thermal band (Landsat TM and ETM+) or two thermal bands (TIRS). This retrieved LST method from Landsat images gets accepted results comparing to in situ data and widely applied worldwide, as well as in Vietnam.

Da Nang is a dynamic urban in Vietnam. The city has the highest urbanization ratio among provinces and municipalities in Vietnam (General Statistics Office, 2013). As consequences, impact of urbanization on the city's environmental condition is presented and needs be identified, particularly on urban thermal environment. Using Landsat images to mapping urban LST in Da Nang city has been addressed in several studies (An et al., 2011; Huyen and Hanh, 2013; Linh and Chuong; 2015). In these studies, the impacts of urbanization on urban thermal environment in Da Nang city are not adequately presented due to short historical data or large spatial studied scale. The purpose of our study is to examine the urban expansion in Da Nang city since the 1990 and the impact of such expansion on the urban thermal environment. In this study, urbanization of $\mathrm{Da}$ Nang city was demonstrated spatially focusing on downtown districts and its impact on urban thermal environment was discussed basing on the change in the thermal differences between urban and rural areas during last 25 years. Result of the study can be used as an important input database for building Da Nang city's environmental plan.

\section{Materials and methods}

\subsection{Study area}

Da Nang is one of the major port cities in Vietnam (in addition to Ho Chi Minh City and
Haiphong) and is commercial and educational center of Central Vietnam. Da Nang has tropical monsoon (hot and humid) climate dominated by a dry season that lasts roughly from April to August, and a wet season from September to March. The humidity rarely drops below $60 \%$ in the city, averaging roughly $80 \%$ and the mean annual temperature is $25.9^{\circ} \mathrm{C}$. As the city has experienced rapid development in the past few decades, the large number of buildings and roads, more cars and air conditioners are trapping excess heat in the city and making it hotter than the surrounding agricultural lands (Opitz-Stapleton, 2014). Because urbanization in Da Nang city has been taken mainly in coastal urban areas than surrounding highland areas, therefore this study focuses on the change in land-covers and LST of six present downtown districts of Da Nang city, including: Lien Chieu, Thanh Khe, Hai Chau, Son Tra, Cam Le and Ngu Hanh Son (Fig. 1), where buildings are dense and LST is much different from suburban areas.

\subsection{Used data}

Multi-generation Landsat data from six different years were acquired. Those are four Landsat 5 Thematic Mapper (TM) images, one Landsat 7 Enhance Thematic Mapper Plus (ETM+) and one Landsat 8 Thermal Infrared Sensor acquired on clear cloud days in summer 1990, 1995, 2000, 2005, 2010 and 2014 (table 1).

All Landsat images used were geo-referenced to a common UTM coordinate and radiometric correction using method of Schroeder et al. (2006) by LANDSAT Program before handling to users. As stated in table 1 , while bands 1 through 5 and band 7 are at a spatial resolution of $30 \mathrm{~m}$, the thermal infrared band (band 6) comes at an original spatial resolution of $120 \mathrm{~m}, 60 \mathrm{~m}$ for Landsat 5 TM images and Landsat 7 ETM+, Landsat 8 TIRS, respectively.

Addition to Landsat data, local historical temperature data recorded by the Weather Underground website (http://www.wunderground.com) and Hydrometeorological station in Central Vietnam (located in Da Nang city) was used to calibrate the estimated models for urban Land surface temperature (LST) from TIRS (2014), TM (2010) 
Vietnam Journal of Earth Sciences 37 (2015) 318-327

and ETM (2000). Current Land-use Map of Da Nang city in 2010 published online in the city's website (http://www.danang.gov.vn/) then used as calibration data for conducting land-cover maps.

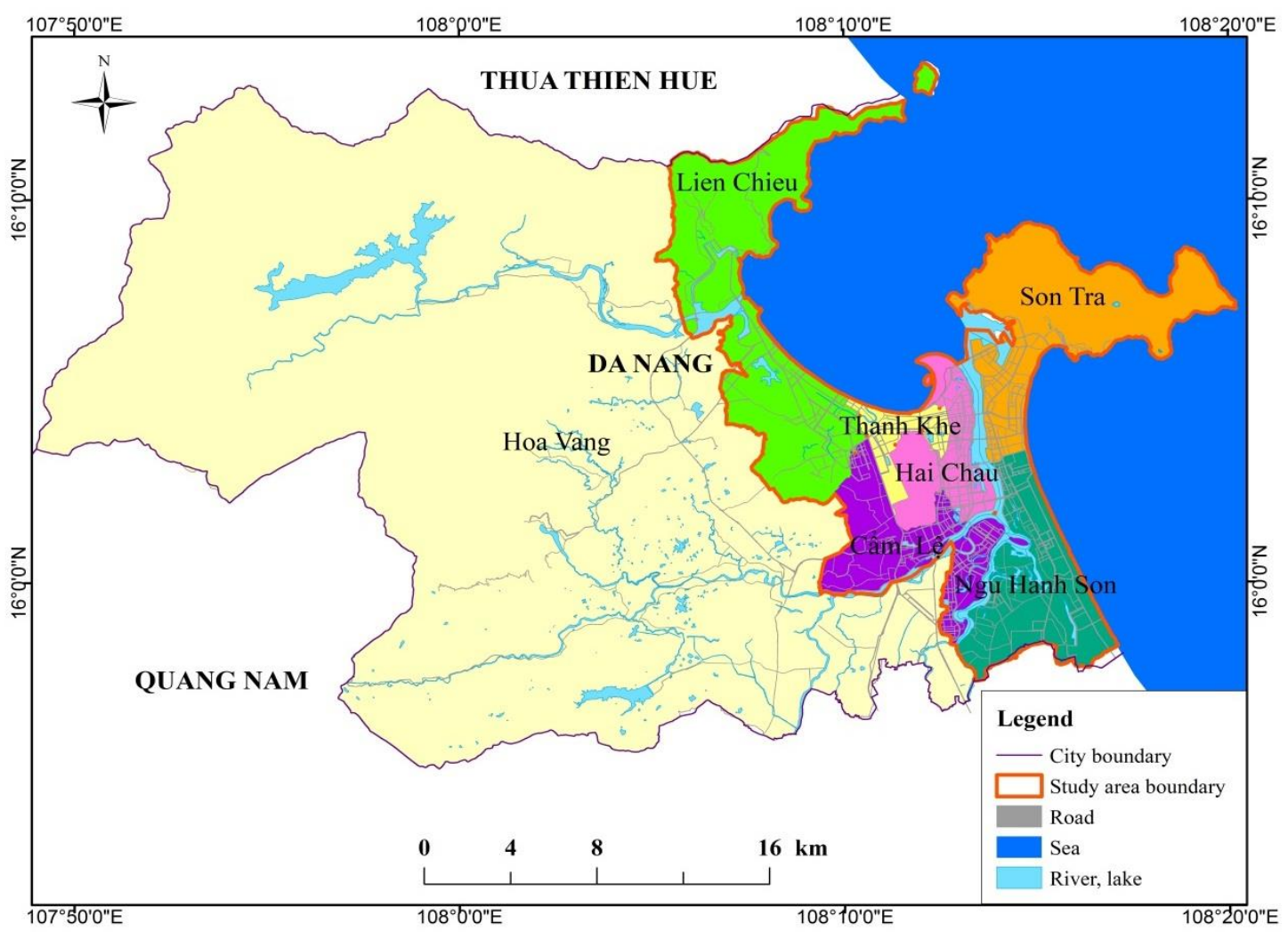

Fig. 1. Location of study area in Da Nang city

Table 1. Used Landsat data

\begin{tabular}{lcccc}
\hline Date of acquiring & Time of acquiring & Landsat sensor types & $\begin{array}{c}\text { Multispectral-bands spatial } \\
\text { resolution }(\mathrm{m})\end{array}$ & \multicolumn{1}{c}{$\begin{array}{c}\text { Thermal bands spatial } \\
\text { resolution }(\mathrm{m})\end{array}$} \\
\cline { 2 - 3 } \cline { 4 - 5 } 7Jul1990 & $9: 26$ & TM & 30 & 120 \\
5Jul1995 & $9: 11$ & TM & 30 & 120 \\
7May2000 & $9: 58$ & ETM+ & 30 & 60 \\
13May2005 & $9: 53$ & TM & 30 & 120 \\
12Jun2010 & $9: 57$ & TM & 30 & 120 \\
22May2014 & $10: 06$ & TIRS & 30 & 60 \\
\hline
\end{tabular}

\subsection{Image processing}

\subsubsection{Land-cover classification}

Satellite image pre-processing prior to the detection of change is immensely needed and has a primary unique objective of establishing a more direct affiliation between the acquired data and biophysical phenomena (Coppin et al., 2004). Images were first pre-processed in ENVI 5.1 for radiometric calibration to convert $\mathrm{DN}$ of multispectral bands into top of atmosphere reflectance basing on methods for each Landsat data types given in Landsat Users Handbooks (NASA, 2012; 2015), then for atmospheric correction using Dark Object subtraction method (Chavez, 1988). Image in 2010 were then assigned basing on per-pixel signatures and differentiating of specific surface reflectance of four classes: built-up, bare-soil, 
D.T. Tu, et al./Vietnam Journal of Earth Sciences 37 (2015)

vegetation and water. Both image statistical and graphical analyses of feature selection and Current Land-use Map of Da Nang city in 2010 were used
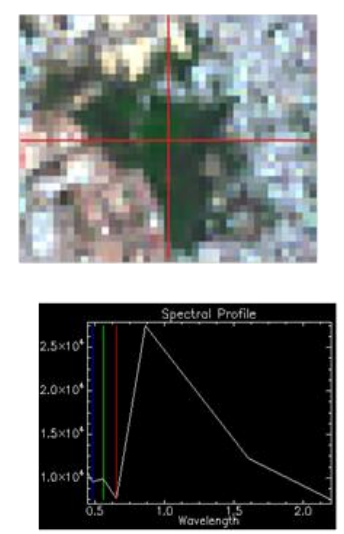

Vegetation
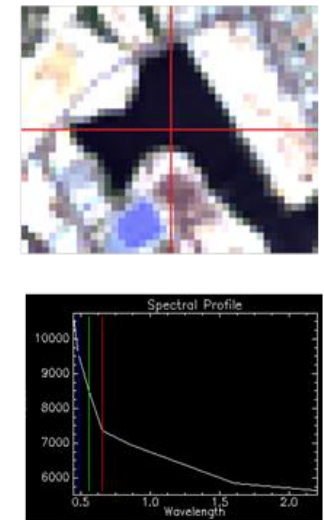

W ater to conduct sample pixels for supervised classification, of which much focusing on built-up, bare-soil areas (Fig. 2).
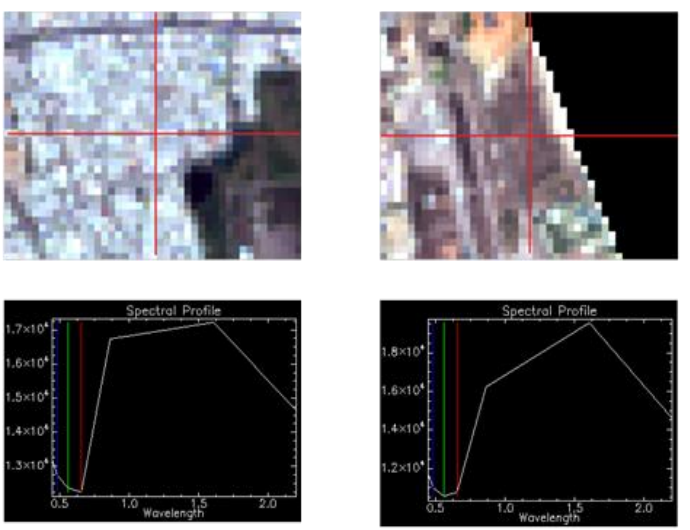

Impervious surface/ built-up area

Bare-soil

Fig. 2. True-color images and spectral graphics of Da Nang city's land-covers

For each of the predetermined land cover type, training samples were selected by delimiting polygons around representative sites. Representative sites were determined using "Current Land-use Map of Da Nang city in 2010" and specific reflectance feature, then were assigned as keys for image classification. Supervised Classification with Minimum Distance was used to classify the images. 6 image scenes were finally classified to detect the spatial expansion of built-up area which indicated for urban area in Da Nang city. The accuracy of these six classified maps was checked with a stratified random sampling method where Kappa coefficients were $0.75 ; 0.78 ; 0.74 ; 0.70 ; 0.80 ; 0.90$ for images of 1990, 1995, 2000, 2005, 2010, and 2014 , respectively.

\subsubsection{LST estimation}

The LST is the radiative skin temperature of the land surface, which plays an important role in the physics of the land surface through the process of energy and water exchanges with the atmosphere. As the near-surface atmospheric water vapor content varies over time due to seasonality and inter-annual variability of the atmospheric conditions, it is inappropriate to directly compare temperature values represented by the LST between multiple periods (Srivanit et al., 2012).
The focus here is on the LST spatial pattern across Da Nang city's urban area.

As proposed Yuan and Bauer (2005), LST was derived from Landsat image through three steps. First, the digital numbers (DNs) of band 6 are converted to radiation luminance or top-ofatmospheric (TOA) radiance ( $L_{\lambda}$, $\mathrm{mW} /\left(\mathrm{cm}^{2} \mathrm{sr} \cdot \mu \mathrm{m}\right)$. In this study, individual pixel data from the extracted region were converted to top of atmosphere (TOA) radiance following:

$$
L_{\lambda}=M_{L} \cdot Q_{C A L}+A_{L}
$$

where $M_{L}$ is band specific multiplicative rescaling factor (radiance_mult_band_10/11); $Q_{C A L}$ is pixel digital number (DN) values and $A_{L}$ is band specific additive rescaling factor (radiance_add_band_10/11). The value of $M_{L}$ and $A_{L}$ is different in Landsat image types (Tab. 2)

Table 2. Resclaing factors and constants values for Landsat images

\begin{tabular}{crrr}
\hline Thông số & TM & ETM+ & TIRS \\
\cline { 3 - 4 } \cline { 3 - 4 } $\mathrm{M}_{\mathrm{L}}$ & 0,055 & 0,067 & 0,0003342 \\
$\mathrm{~A}_{\mathrm{L}}$ & 1,8243 & $-0,06709$ & 0,1 \\
$K_{1}$ & 607,76 & 666,09 & 774,89 \\
$K_{2}$ & 1260,56 & 1282,7 & 1321,08 \\
\hline
\end{tabular}

The radiance then was converted to surface temperature using the Landsat specific estimate of the Planck curve as Eq. (2): 
Vietnam Journal of Earth Sciences 37 (2015) 318-327

$$
T_{K}=\frac{K_{2}}{\ln \left(\frac{K_{1}}{L_{\lambda}}+1\right)}
$$

where is $T_{K}$ the temperature in Kelvin $(\mathrm{K}), K_{1}$ is the prelaunch calibration of constant 1 in unit of $\left(\mathrm{W} / \mathrm{m}^{2} \mathrm{sr} \cdot \mu \mathrm{m}\right)$ and $K_{2}$ is the prelaunch calibration constant 2 in Kelvin. $K_{1}$ and $K_{2}$ are different for each type of Landsat images (Tab. 2).

The final apparent surface temperature on Celsius $\left({ }^{\circ} \mathrm{C}\right)$ can be calculated the following equation:

$$
T\left({ }^{o} C\right)=T_{K}-273.15
$$

where $T\left({ }^{\circ} \mathrm{C}\right)$ is the temperature in Celsius $\left({ }^{\circ} \mathrm{C}\right)$, $T_{K}$ is the temperature in Kelvin $(\mathrm{K})$.

LST then was corrected using directly linear regression analysis between image-based estimated LST data and in situ LST data retrieved from the Weather Underground website and Vietnam Hydrometeorological Data Center and model for tropical area (Qin et al., 2001, Sun et al., 2010; Liu and Zhang, 2011). Estimated LST and in situ LST from 3 pixels, corresponding to 3 in situ temperature record stations, of each Landsat data (TM in 2010; ETM+ in 2000 and TIRS in 2014) were linear statistical analyzed for getting estimated LST models. Accordingly, LST for Da Nang city was estimated from each Landsat image types following below equations:

$$
\begin{aligned}
& \text { For TM: } \mathrm{LST}=0.55 \times \mathrm{T}\left({ }^{\circ} \mathrm{C}\right)+18.1 \\
& \text { For ETM+: } \mathrm{LST}=0.55 \times \mathrm{T}\left({ }^{\circ} \mathrm{C}\right)+14.18 \\
& \text { For TIRS: } \mathrm{LST}=0.82 \times \mathrm{T}\left({ }^{\circ} \mathrm{C}\right)+6.24
\end{aligned}
$$

\section{Results and discussion}

\subsection{Urbanization of Da Nang city during 1990- 2015}

Urbanization leads to increasing of impervious surface where lands are mainly dominated by artificial structures, such as pavements (roads, sidewalks, driveways and parking lots) that are covered by impenetrable materials such as asphalt, concrete, brick, stone and rooftops. Obtained classification maps from Landsat images in 1990, 1995, 2000, 2005, 2010 and 2014 of six central downtown districts of Da Nang city showed a significant urbanization in the city through observed expansion of built-up area corresponding to impervious surface (Fig. 3). Accordingly, the area of impervious surface in Da Nang city which indicates for urban buildings, road, factories, commercial centers, increased from 4,485 ha in 1990 to 4,759 ha in 1995 (increased $5.8 \%$ of the 1990); 5,232 ha in 2000 (increased $9 \%$ of the 1995); 5,647 ha in 2005 (increased $7.3 \%$ of the 2000); 8,289 ha in 2010 (increased $31.9 \%$ of 2005 ) and 8,634 ha in 2014. Particularly, during period of 2005 - 2010, the urban expanded in high velocity compared other periods that evidently proved by the increase of impervious surface area from 5,647 ha (in 2005) to 8,289 ha (in 2010). This urban expansion stage is corresponding to a strong social - economic growth of Da Nang during period of 2005-2010.

According to classified results (Tu et al., 2015), most of the urban expansion resulted from the conversion of agricultural land which is presented as vegetation class in the maps. This study also indicated that exception for green space in Hai Van Cape and Son Tra headland, all green spaces in the western area of Lien Chieu, Cam Le, Ngu Hanh Son districts where were mostly used for short term vegetables cultivation (Da Nang city's landuse maps in 2005, 2010) has been converted gradually into bare-soil or built-up areas/impervious surface due to urbanization.

\subsection{Spatial pattern of LST}

Remote sensing provides not only a measure of LST of the entire Da Nang urban area, but also indicates clearly the spatial extent of the area covered by top $5 \%$ highest LST. Figure 4 presents the spatial pattern of LST in Da Nang urban area on 6 image acquired dates in summer 1990, 1995, 2000, 2005, 2010 and 2014. It was found that high LST $\left(>32^{\circ} \mathrm{C}\right)$ was mainly located in central urban areas, particularly in Thanh Khe and Hai Chau districts where have been mostly covered by buildings, roads, offices and commercial centers. Whereas, low LST $\left(<28^{\circ} \mathrm{C}\right)$ was mainly located in Hai Van Pass and Son Tra Headland areas where 
D.T. Tu, et al./Vietnam Journal of Earth Sciences 37 (2015)

area characterized by high elevation and are mostly covered by forests (Fig. 5).

There are two main rivers flow through $\mathrm{Da}$ Nang urban areas: Han River (in the city center) and $\mathrm{Cu}$ De River (in Lien Chieu district). It was clear that LST in Han and $\mathrm{Cu}$ De rivers is much lower than it in surrounding areas, particularly compared to downtown areas. These rivers showed an important role in local climate adjustment, particularly in the 1990 s while local residence buildings were not concentrated with high density along the river sides as recent years.

The LST showed significantly increase in the western parts of Lien Chieu, Cam Le and Ngu
Hanh Son districts. Since 2010 up to present, these lands were agricultural lands before has been converted into built-up and bare soil areas (Fig. 3), therefore LST of these areas becomes much higher than it in the past and same to LST in downtown areas (Fig. 4). The LST always presents at high level along the coast, particularly along the coast from Son Tra Headland to Non Nuoc Beach where topsoil is covered mostly by dry light sand or concrete layers due to artificial infrastructure for beach tourism. Dry sand always heats up faster than other soil types, therefore this area got high LST at observed time (at about10:30 am local time when Landsat satellite acquired data in Da Nang) as presented in Figure 4.
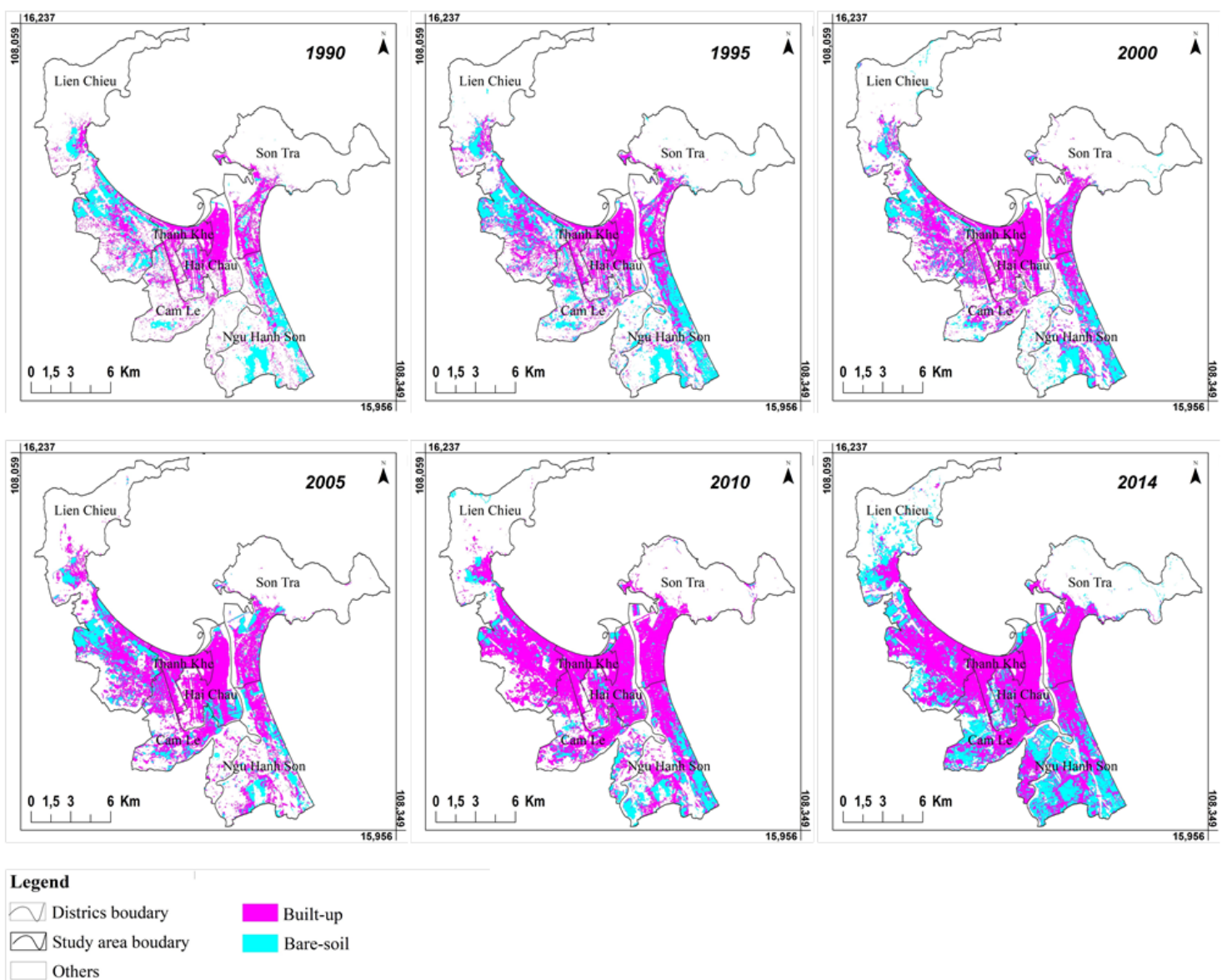

Fig. 3. Spatial expansion of built-up area that indicated for urban area in present 6 downtown districts of Da Nang city during 1990-2014 
Vietnam Journal of Earth Sciences 37 (2015) 318-327
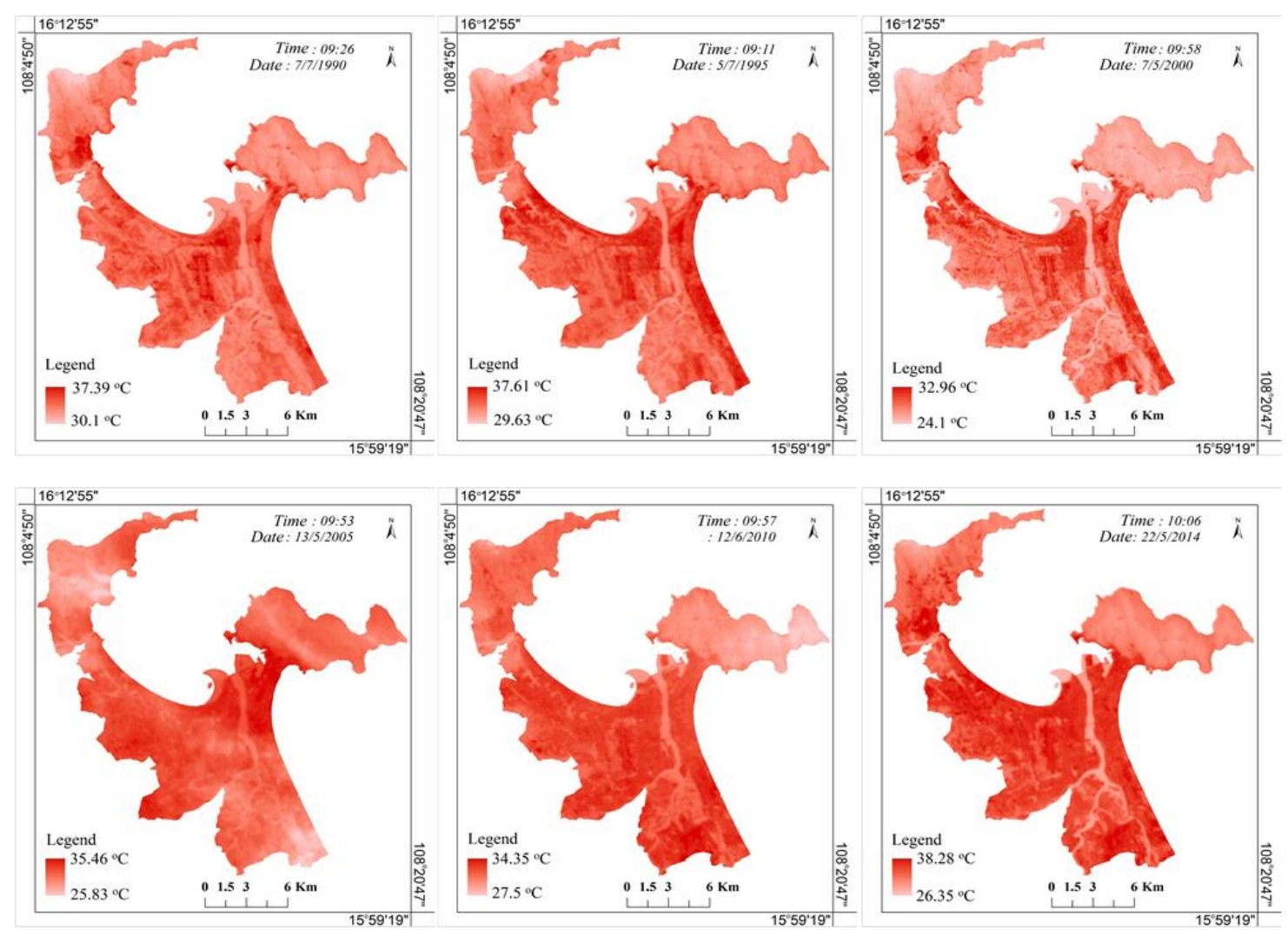

Fig. 4. Spatial LST pattern in Da Nang's urban area on 6 studied dates

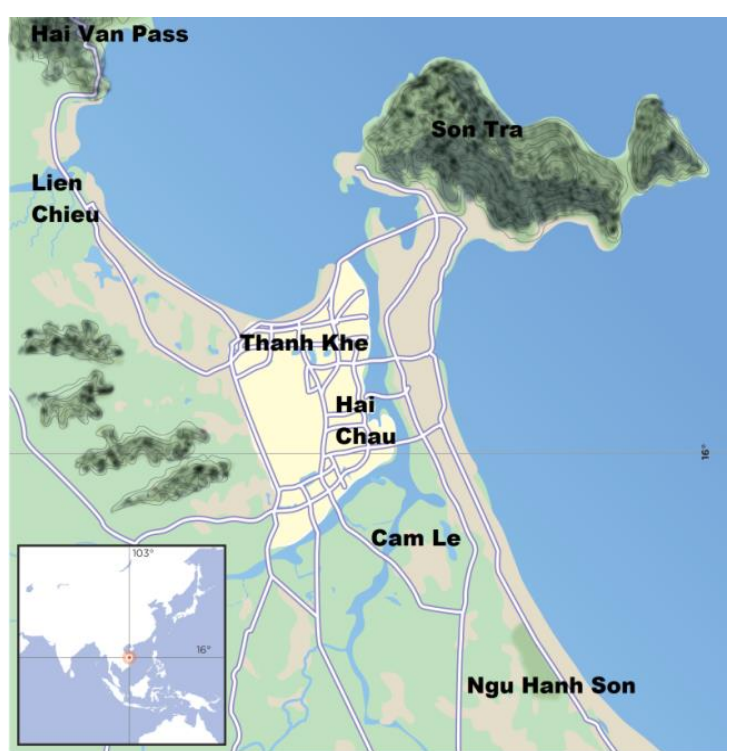

Fig. 5. Da Nang city's simple topographic map (modified after Opitz-Stapleton, 2014)
Health research indicates that a variety of health impacts begin to emerge through a broad range of air temperature and humidity conditions, especially if the individual is engaged in physical activity (Smith et al., 2014). According to the simple heat index table from the U.S. National Oceanic and Atmospheric Administration (NWS, 2014), at humidity roughly about $80 \%$ as in Da Nang, at air temperature higher than $30^{\circ} \mathrm{C}$, healthy person who doing strenuous physical activity or/with prolonged exposure will be exhausted. At air temperature higher than $35^{\circ} \mathrm{C}$, the caution may be extremely to heat cramp. Among 6 days of observation, there are three days the LST of Da Nang city got higher than $35^{\circ} \mathrm{C}$ at about local 10:30 am (Landsat images acquiring time) which suggested that air temperature may reach higher than $35^{\circ} \mathrm{C}$ in the noon and early afternoon. The areas with LST value higher than $35^{\circ} \mathrm{C}$ LST were located mostly in the downtown area and industrial parks (Fig. 6). 
D.T. Tu, et al./Vietnam Journal of Earth Sciences 37 (2015)
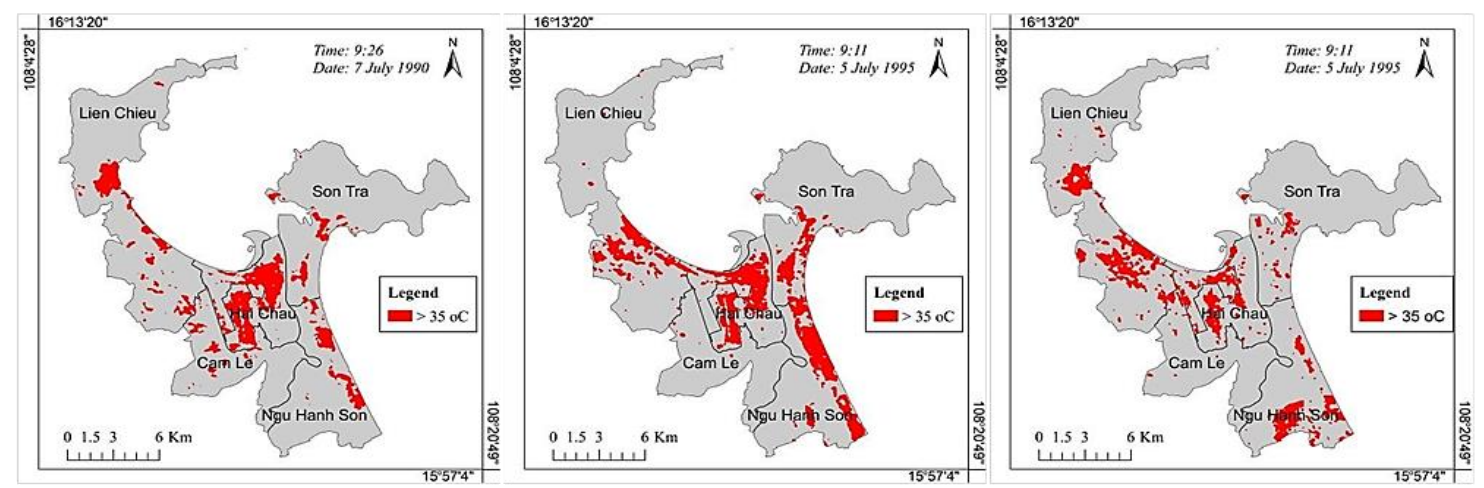

Fig. 6. Locations of over $35^{\circ} \mathrm{C}$ LST areas on observed days in 1990, 1995 and 2014

\subsection{Impact of urbanization on the LST}

The impact of urbanization on the LST in the case of Da Nang city in this study is confirmed by comparing observational data from cities and surrounding rural areas. Fig. 4 modelled the differential temperature between LST in built-up and surrounding areas in Da Nang urban by the decrease of red color tone. In this figure, built-up areas were mostly covered by strong red tone which indicated for maximum LST while surrounding areas such as Hai Van, Son Tra or Han River were mostly covered by light red tone which assigned as minimum LST. Accordingly, the differential temperature between LST in builtup and surrounding areas can be recognized as the differential temperature between maximum LST to minimum LST detected in each observed day.
Fig. 7 showed relationship between this differential temperature and total area of built-up land-cover by time. Although observing on different air-temperature dates, the differential temperature of LST in built-up and surrounding areas has increased (Fig. 7) from $7.3^{\circ} \mathrm{C}$ in 1990 to $8.0^{\circ} \mathrm{C}$ in $1995 ; 8.9^{\circ} \mathrm{C}$ in $2000 ; 10^{\circ} \mathrm{C}$ in 2005 ; $11.9^{\circ} \mathrm{C}$ in 2014 while built-up areas has increased from 4,485 ha to 4,759 ha; 5,232 ha; 5,647 ha; 8,289 ha; 8,634 ha, respectively. Both trend lines of built-up area and the differential temperature of LST in built-up and surrounding areas showed an upward trend (with correlation coefficient of 0.4) indicating impact of urbanization to urban thermal. Accordingly, the more area was built-up, the more differential temperature of LST in built-up and surrounding areas was detected. In other words, urbanization causes the increase of near surface temperature for the urban area.

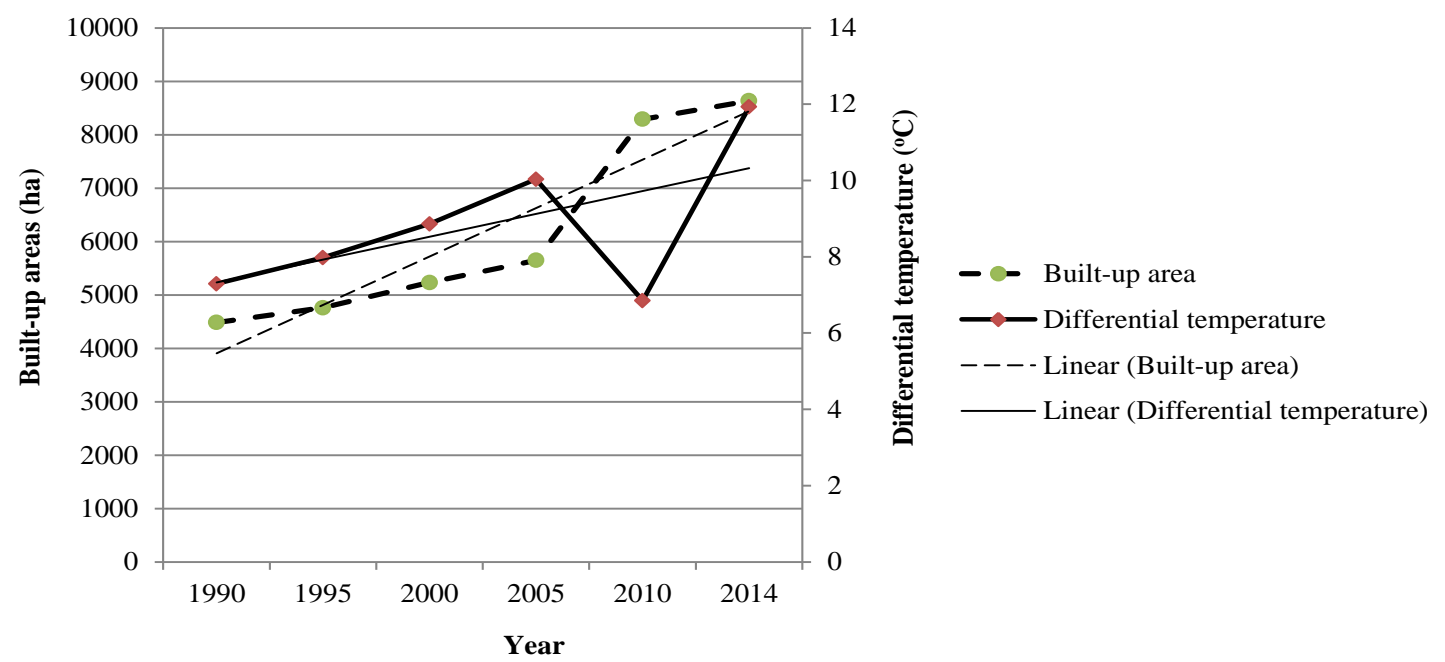

Fig. 7. Relationship between differential temperature of LST in built-up and surrounding areas and total area of built-up land-cover in Da Nang city through 1990-2014 
Vietnam Journal of Earth Sciences 37 (2015) 318-327

Spatially, urbanization leads the expansion of area covered by the highest LST (Fig. 4). The highest LST areas firstly concentrated only in high density residential buildings in Thanh Khe, Hai Chau districts in the $1990 \mathrm{~s}$, and then extended to cover mostly 6 downtown districts of Da Nang at presents.

It was notified that maximum value of LST may influence on the differential temperature between downtown and suburban areas (as observed in 2010), this parameter is showed an upward trend and conformable to the increase of total urban area.

\section{Conclusion}

This study focuses on the impact of urbanization to the city's thermal environment through the case of Da Nang city by monitoring the change in urban area, LST and the differential LST between downtown and suburban areas by the time. The results obtained in this work show that Da Nang city's urban area expanded twice from 1990 to 2014, leading the expansion of the highest LST from centers of Hai Chau and Thanh Khe districts in the $1990 \mathrm{~s}$ to mostly 6 present downtown districts. The impact of urbanization on the LST in Da Nang city additionally confirmed by the increase of differential temperature between downtown and suburban areas, from $7.3^{\circ} \mathrm{C}$ in 1990 to $11.9^{\circ} \mathrm{C}$ in 2014 . In order to create an environment plan for Da Nang city, the urban thermal environment should be investigated more detail to reform the city structure toward proactive response to climate change and environment protection.

\section{References}

An, T.T, Dieu, N.T, Minh T.P., 2011: Researching the land surface temperature in Danang city from the satellite image of Landsat 7 ETM+, National GIS Conference 2011, 14-21.

Castrence, M., Nong, D.H., Tran, C.C, Young, L., Fox J., 2014: Mapping Urban Transitions Using Multi-Temporal Landsat and DMSP-OLS Night-Time Lights Imagery of the Red River Delta in Vietnam, Land 2014, 3, 148-166.

Chavez Jr. P. S., 1988: An improved dark-object subtraction technique for atmospheric scattering correction of multispectral data,Remote Sensing of Environment, 24 (3): 459-479.

Chen, X.L., Zhao, M.Z., Li, P.X., Yin, Z.Y., 2006: Remote sensing image-based analysis of the relationship between urban heat island and land use/cover changes, Remote Sensing of Environment, 104, 133-146.

Coppin, P., Jonckheere, I., Nackaerts, K., Muys, B., Lambin, E., 2004: Digital change detection methods in ecosystem monitoring: a review,Int. J. Remote Sensing 25(9): 1565-1596.

General Statistics Office, 2013: Statistical Handbook of Vietnam 2013, Statistical Publishing House.

Huang, S., Taniguchi, M., Yamano, M., Wang, C., 2009: Detecting urbanization effects on surface and subsurface thermal environment - A case study of Osaka. Science of Total Environment, 407, 3142-3152.

Huyen, H.T.D, Hanh L.N, 2013: Analysis of the relationship between surface temperature and buffer Danang, Journal of Science, Technology University of Da Nang, 7 (68): 31-37.

Li Y-B, Shi T., Yang Y.-J., 2015: Satellite-based investigation and evaluation of the observational environment of meteorological stations in Anhui province, China, Pure Appl. Geophys., 172 (6), 1717-1733.

Linh, N.H.K., Chuong H.V, 2015: Assessing the impact of urbanization on urban climate by remote sensing perspective: a case study in Danang city, Vietnam. The International Symposium on Remote Sensing of Environment, 11-15 May 2015, Berlin, Germany, 207-212.

Liu, L., Zhang, Y., 2011: Urban Heat Island Analysis Using the Landsat TM Data and ASTER Data: A Case Study in Hong Kong, Remote Sens. 3, 1535-1552; doi:10.3390/rs3071535

NASA, 2012: Landsat 7 Science Data Users Handbook. 186 p (http://landsathandbook.gsfc.nasa. gov/pdfs/Landsat7_Handbook.pdf)

NASA,2015: Landsat 8 Data Users Handbook. 106p (https://landsat.usgs.gov/documents/ Landsat8DataUsersHandbook.pdf)

Opitz-Stapleton S., 2014: Da Nang, Vietnam: Climate Change Impacts on Heat Stress by 2050. Boulder, CO: Institute for Social and Environmental Transition-International.

Qin, Z.; Zhang, M.; Amon, K; Pedro, B., 2010: Mono-window Algorithm for retrieving land surface temperature from Landsat TM 6 data, Acta Geogr. Sinica, 56, 456-466. 


\section{D.T. Tu, et al./Vietnam Journal of Earth Sciences 37 (2015)}

Rodgers M.O., Stone B.J., 2001: Urban Form and Thermal Efficiency: How the Design of Cities Influences the Urban Heat Island effect, Journal of the American Planning Association, 67 (2), 186-198

Sailor, D. J., 2002: Urban Heat Islands, Opportunities and Challenges for Mitigation and Adaptation. Sample Electric Load Data for New Orleans, LA (NOPSI, 1995). North American Urban Heat Island Summit. Toronto, Canada. 1-4 May 2002. Data courtesy Entergy Corporation.

Schroeder, T.A., Canty, M.J, Yang, Z., 2006: Radiometric correction of multi-temporal Landsat data for characterization of early successional forest patterns in western Oregon. Remote Sensing of Environment; 103:16-26.

Shi, T., Huang, Y., Wang, H., Shi, C-E., Yang, Y-J., 2015: Influence of urbanization on the thermal environment of meteorological station: Satellite-observed evidence. Advances in Climate Change Research, 6 (1), 7-15.

Smith, K.R., Woodward A., Campbell G., Lendrum D., 2014: Chapter 11. Human Health: Impacts, Adaptation, and CoGBenefits. In (Climate Change 2014: Impacts, Adaptation, and Vulnerability, Contribution of Working Group II to the Fifth Assessment Report of the IPCC, Cambridge University Press: Cambridge.

Srivanit M., Hokao K., Phonekeo V., 2012: Assessing the Impact of Urbanization on Urban Thermal Environment: A
Case Study of Bangkok Metropolitan, International Journal of Applied Science and Technology 2 (7): 243-256.

Sun, Q.; Tan, J.; Xu, Y., 2010: An ERDAS image processing method for retrieving LST and describing urban heat evolution: A case study in the Pearl River Delta Region in South China, Environ. Earth Sci. 59, 1047-1055.

Tu, D.T, Hai T.Q, Ha, N.T.T, Ngan, N.T.M, 2015: Monitoring urbanization of Da Nang city using multi-generational Landsat imagery for urban environmental planning, Journal of Environment, 8, 6-13.

Van, T.T, Bao, H.D.X, 2008: A study on urban development through land surface temperature by using remote sensing: in case of Ho Chi Minh City. VNU Journal of Science, Earth Sciences 24, 160-167.

Van, T.T, Bao, H.D.X, 2010: Characteristics of Urban Thermal Environment from Satellite Remote Sensing Data in Ho Chi Minh City, Vietnam. The $1^{\text {st }}$ International Electronic Conference on Remote Sensing.

Yuan, F., Sawaya, K. E., Loeffelholz, B. C., \& Bauer, M. E. 2005: Land cover mapping and change analysis in the Twin Cities Metropolitan Area with Landsat remote sensing, Remote Sensing of Environment, 98(2.3), 317-328.

Weng Q., 2001: A remote sensing-GIS evaluation of urban expansion and its impact on surface temperature in the Zhujiang Delta, China, Int. J. Remote Sens., 22 (10), 19992014 